Article

\title{
Diterpenoids from the Endophytic Fungus Botryosphaeria sp. P483 of the Chinese Herbal Medicine Huperzia serrata
}

\author{
Yan-Mei Chen ${ }^{1,2}$, Yin-He Yang ${ }^{1}$, Xiao-Nian Li ${ }^{1}$, Cheng Zou ${ }^{2}$ and Pei-Ji Zhao ${ }^{1, *}$ \\ 1 State Key Laboratory of Phytochemistry and Plant Resources in West China, \\ Kunming Institute of Botany, Chinese Academy of Sciences, Kunming 650201, China; \\ E-Mails: ymchen2015@126.com (Y.-M.C.); yyh8612@126.com (Y.-H.Y.); \\ lixiaonian@mail.kib.ac.cn (X.-N.L.) \\ 2 School of Pharmaceutical Sciences, Kunming Medical University, Kunming 650500, China; \\ E-Mail: zouchengkm@126.com
}

* Author to whom correspondence should be addressed; E-Mail: pjzhao@outlook.com; Tel.: +86-871-65-223-111; Fax: +86-871-65-150-227.

Academic Editor: Thomas J. Schmidt

Received: 16 July 2015 / Accepted: 9 September 2015 / Published: 17 September 2015

\begin{abstract}
Two new tetranorlabdane diterpenoids, named botryosphaerins G (1) and H (2), were isolated from the solid fermentation products of Botryosphaeria sp. P483 along with seven known tetranorlabdane diterpenes (3-9). Their structures were elucidated by extensive analysis, including 1D and 2D nuclear magnetic resonance (NMR) spectroscopy, and high-resolution electrospray ionization mass spectrometry (HR-ESI-MS). Their absolute configuration was confirmed by single-crystal X-ray diffraction analyses using the anomalous scattering of $\mathrm{Cu} \mathrm{K \alpha}$ radiation. All of the isolated compounds were tested for activity against phytopathogenic fungi and nematodes. Compounds $\mathbf{2}$ and $\mathbf{3}$ showed antifungal activity and compound $\mathbf{2}$ showed weak nematicidal activity.
\end{abstract}

Keywords: Botryosphaeria sp. P483; tetranorlabdane diterpenoid; X-ray crystallography; antifungal activity; nematicidal activity 


\section{Introduction}

Endophytic fungi, defined functionally by their occurrence in plant tissue without causing any overt effects [1], are present in almost all plants and are important sources of natural products [2]. The products of endophytic microbes and their uses in medicine, agriculture and industry have been reviewed [3]. The increasing number of new compounds discovered in endophytes demonstrates their potential for producing many more previously unknown natural products, which are still to be exploited for their potential applications. Huperzia serrata (Thunb.) Trev. (Huperziaceae) is a Chinese traditional medicine that produces huperzine A, a potential therapeutic agent for treatment of Alzheimer's disease that has been extensively studied in recent years [4]. In our search for new active compounds from endophytic microorganisms, a series of novel compounds were previously identified [5-7]. During ongoing research on plant endophytic microorganisms, an isolate of Botryosphaeria sp. P483, obtained from the tissue of $H$. serrata, has been investigated. A systematic chemical study was performed and resulted in the isolation of new botryosphaerin G (1) and botryosphaerin $\mathrm{H}(2)$, along with seven known diterpenoids, 13,14,15,16-tetranorlabd-7-en-19,63:12,17-diolide (3) [8], botryosphaerin A (4) [9], 3a,10b-dimethyl1,2,3,3a,5a,7,10b,10c-octahydro-5,8-dioxa-acephenanthrylene-4,9-dione (5) [10], acrostalidic acid (6) [11], botryosphaerin B (7), LL-Z1271ß (8) and acrostalic acid (9) [9] (Figure 1).

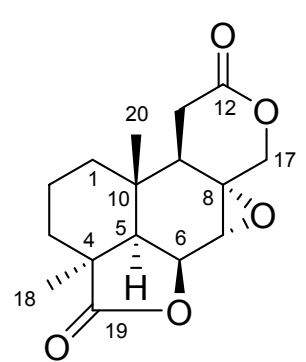

1<smiles>C[C@]12CCC[C@@H](C(=O)O)[C@H]1C=CC1COC(=O)C[C@H]12</smiles>

6

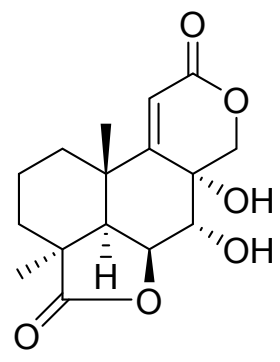

2<smiles>C[C@]12CCC[C@]3(C)CC(=O)O[C@@H]3C=CC1=CC(=O)OC2</smiles>

3

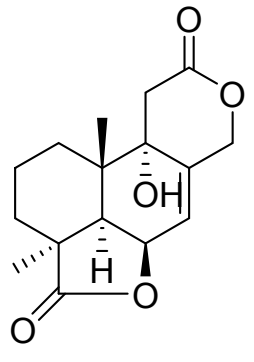

4<smiles>C[C@]12CCC[C@]3(C)COC(=O)C[C@H]3C=C1COC(=O)O2</smiles>

5<smiles>C[C@]12CCC[C@@](C)(C(=O)O)[C@@H]1C=C[C@]1(CO)OC(=O)C[C@H]12</smiles>

7<smiles>C=C1C(O)C[C@H]2[C@@H](C)CCC[C@]2(C)[C@H]1CC(=O)O</smiles>

8<smiles>C=C1CC[C@H]2[C@@H](C(=O)O)CCC[C@]2(C)[C@H]1CC(=O)O</smiles>

9

Figure 1. Chemical structures of compounds 1-9 from Botryosphaeria sp. P483.

\section{Results and Discussion}

\subsection{Characterization}

The nucleotide sequences for the ITS1-5.8S rDNA-ITS4 region of the fungal strain P483 was registered in the GenBank database with the accession number KT213569, and the strain was determined to be Botryosphaeria sp. from the internal transcript spacer (ITS) analysis. 
Compound 1 was obtained as colorless needles. The negative (HR-ESI-MS) data indicated a molecular formula of $\mathrm{C}_{16} \mathrm{H}_{20} \mathrm{O}$ 5 based on the $[\mathrm{M}+\mathrm{Na}]^{+}$ion signal at $m / z$ 315.1203 (calc. 315.1208). The ${ }^{13} \mathrm{C}-\mathrm{NMR}$ and distortionless enhancement by polarization Transfer (DEPT) spectra (Table 1) revealed five quaternary carbons $\left(\delta_{\mathrm{C}} 180.4,171.6,60.6,41.7\right.$ and 34.0$)$, four methines $\left(\delta_{\mathrm{C}} 72.4,53.6,49.2\right.$ and 43.2$)$, five methylenes $\left(\delta_{\mathrm{C}} 71.2,32.0,28.51,28.45\right.$, and 17.5$)$ and two methyls ( $\delta_{\mathrm{C}} 24.4$ and 17.6). According to the ${ }^{1} \mathrm{H}-\mathrm{NMR}$ (Table 1$)$, two singlet methyl signals $\left(\delta_{\mathrm{H}} 1.28\right.$ and 0.93$)$ were also present, which suggested that compound 1 was a tetranorlabdane diterpene [9-11]. In the COSY spectrum (Figure 2 and Figure S5), three fragments were deduced to be -C-1-C-2-C-3-, -C-5-C-6-C-7- and -C-9-C-11-from a complete interpretation of the key correlations. The HMBC experiment (Figure 2 and Figure S4) showed that the methyl protons at $\delta_{\mathrm{H}} 0.93$ (H-20) correlated with the carbons at $\delta_{\mathrm{C}} 49.2$ (C-5), 43.2 (C-9), 34.0 (C-10) and $32.0(\mathrm{C}-1)$; the protons at $\delta_{\mathrm{H}} 2.21$ and $1.49(\mathrm{H}-3)$ correlated with carbons at $\delta_{\mathrm{C}} 180.4(\mathrm{C}-19), 49.2$ (C-5), 41.7 (C-4), 32.0 (C-1), $24.4(\mathrm{C}-18)$ and 17.6 (C-20); the proton at $\delta_{\mathrm{H}} 4.90(\mathrm{H}-6)$ correlated with carbons at $\delta_{\mathrm{C}} 60.6(\mathrm{C}-8), 53.6(\mathrm{C}-7)$ and $34.0(\mathrm{C}-10)$; the methyl protons at $\delta_{\mathrm{H}} 1.28(\mathrm{H}-18)$ correlated with carbons at $\delta_{\mathrm{C}} 180.4(\mathrm{C}-19), 49.2(\mathrm{C}-5), 41.7(\mathrm{C}-4)$ and $28.51(\mathrm{C}-3)$; the protons of the oxygenated methylene at $\delta_{\mathrm{H}} 4.41$ and 4.05 (H-17) correlated with carbons at $\delta_{\mathrm{C}} 171.6(\mathrm{C}-12), 60.6$ (C-8), 53.6 (C-7) and 43.2 (C-9). These data, together with other correlations (Figure 2), established the planar structure. The NOESY experiment showed NOEs between H-6 and H-18, H-5; H-5 and H-9; H-20 and H-7, H-11 (Figure 3 and Figure S6). These data supported the relative configurations of C-5, C-6, C-7, C-9, $\mathrm{C}-18$ and $\mathrm{C}-20$. The final refinement of the $\mathrm{Cu} \mathrm{K \alpha}$ data resulted in a Flack parameter $=0.2(3)$ and a Hooft parameter $=0.07(6)$ for 1024 Bijvoet pairs $[12,13]$, allowing an explicit assignment of the complete absolute configuration of 1 as shown in Figure 1 with $4 S, 5 R, 6 S, 7 R, 8 R, 9 R$ and $10 S$ stereochemistry, which was named as botryosphaerin G (Figure 4).

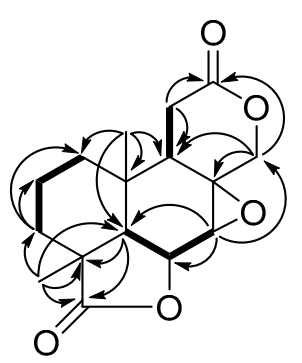

1

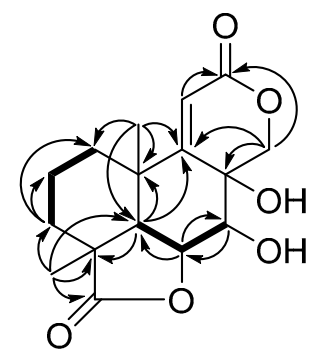

2

Figure 2. Key ${ }^{1} \mathrm{H}-{ }^{1} \mathrm{H}$ COSY (bold line) and $\mathrm{HMBC}$ (arrows) correlations for $\mathbf{1}$ and $\mathbf{2}$.
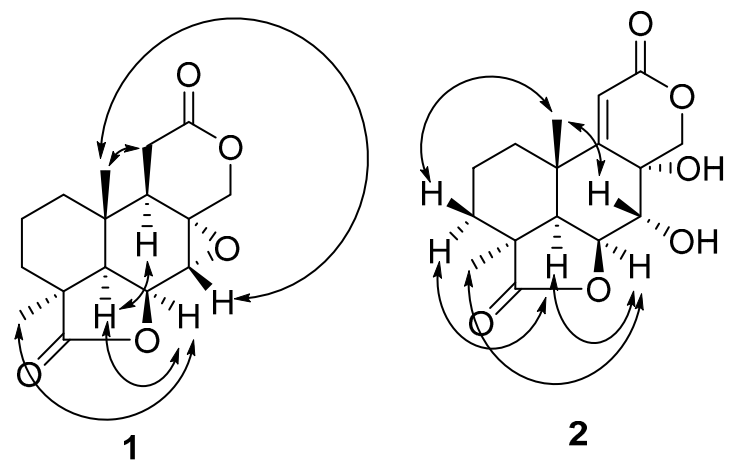

Figure 3. The NOESY correlations in $\mathbf{1}$ and $\mathbf{2}$. 


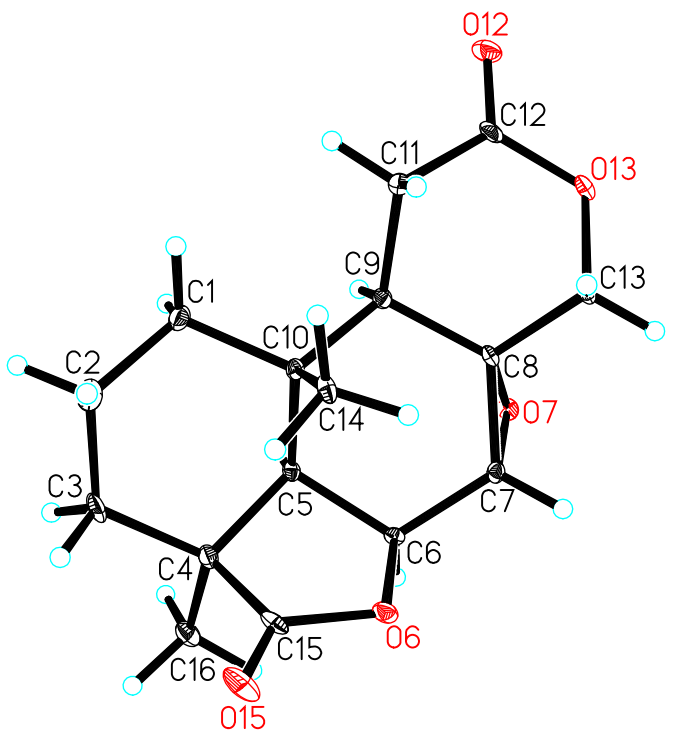

Figure 4. X-ray crystal structure of 1.

Compound 2 was obtained as a colorless solid. The positive HR-ESI-MS data indicated a molecular formula of $\mathrm{C}_{16} \mathrm{H}_{20} \mathrm{O}_{6}$ based on the $[\mathrm{M}+\mathrm{H}]^{+}$at $m / z$ 309.1331 (calc. 309.1338), and this was supported by the ${ }^{13} \mathrm{C}-\mathrm{NMR}$ and DEPT data (Table 1$)$.

Table 1. NMR data of compounds 1 and 2.

\begin{tabular}{|c|c|c|c|c|c|c|}
\hline \multirow{2}{*}{ Position } & \multicolumn{3}{|c|}{$1^{a}$} & \multicolumn{3}{|c|}{$2^{b}$} \\
\hline & $\delta_{H}(m u l t i, J$ in $\mathbf{H z})$ & $\delta_{\mathbf{C}}$ & НМВС & $\delta_{H}($ multi, $J$ in $\mathrm{Hz})$ & $\delta_{\mathbf{C}}$ & НMBC \\
\hline $1 \beta$ & $1.54, \mathrm{~m}$ & \multirow{2}{*}{32.0} & 3,10 & $1.76, \mathrm{~m}$ & \multirow{2}{*}{33.9} & $2,3,5,9,10,20$ \\
\hline $1 \alpha$ & $1.15, \mathrm{~m}$ & & $3,9,10$ & $1.48, \mathrm{~m}$ & & $2,3,10,20$ \\
\hline $2 \beta$ & $1.65, \mathrm{~m}$ & \multirow{2}{*}{17.5} & $1,3,4$ & $1.60, \mathrm{~m}$ & \multirow{2}{*}{17.7} & $2,4,10$ \\
\hline $2 \alpha$ & $1.59, \mathrm{~m}$ & & $1,3,4$ & $1.43, \mathrm{~m}$ & & 1,3 \\
\hline $3 \beta$ & $2.21, \mathrm{dt}, 14.4,5.3$ & \multirow{2}{*}{28.51} & $1,4,5,18,19,20$ & $2.21, \mathrm{~m}$ & \multirow{2}{*}{27.8} & $1,2,4,5,18,19$ \\
\hline $3 \alpha$ & $1.49, \mathrm{~m}$ & & $1,4,5,18,19,20$ & $1.35, \mathrm{~m}$ & & $1,2,4,5,18,19$ \\
\hline 4 & - & 41.7 & - & - & 42.1 & - \\
\hline 5 & $1.67, \mathrm{~d}, 4.7$ & 49.2 & $1,4,10,18,19,20$ & $2.86, \mathrm{~d}, 5.5$ & 47.0 & $1,3,4,9,10,18,19,20$ \\
\hline 6 & $4.90, \mathrm{~d}, 4.7$ & 72.4 & $7,8,10$ & $5.40, \mathrm{t}, 5.5$ & 84.0 & $4,7,10$ \\
\hline 7 & 3.56 , brs & 53.6 & $5,6,17$ & $4.73, \mathrm{~d}, 5.5$ & 71.8 & 6,17 \\
\hline 8 & - & 60.6 & - & - & 68.5 & - \\
\hline 9 & $1.90, \mathrm{dd}, 6.4,11.4$ & 43.2 & $5,8,10,11,12,20$ & - & 168.0 & - \\
\hline 10 & - & 34.0 & - & - & 35.7 & - \\
\hline $11 \alpha$ & $2.70, \mathrm{dd}, 6.4,15.2$ & \multirow{2}{*}{28.45} & $8,9,10,12$ & \multirow{2}{*}{$6.11, \mathrm{~s}$} & \multirow{2}{*}{114.9} & \multirow{2}{*}{$8,9,10,12,20$} \\
\hline $11 \beta$ & $2.54, \mathrm{dd}, 11.4,15.2$ & & $8,9,10,12$ & & & \\
\hline 12 & - & 171.6 & - & - & 164.7 & - \\
\hline $17 \beta$ & $4.41, \mathrm{~d}, 12.8$ & \multirow{2}{*}{71.2} & $7,8,9,12$ & $5.18, \mathrm{~d}, 11.9$ & \multirow{2}{*}{75.7} & $8,9,10$ \\
\hline $17 \alpha$ & $4.05, \mathrm{~d}, 12.8$ & & $7,8,9,12$ & $4.62, \mathrm{~d}, 11.9$ & & 8 \\
\hline 18 & $1.28, \mathrm{~s}$ & 24.4 & $3,4,5,19$ & $1.19, \mathrm{~s}$ & 24.4 & $4,5,19,20$ \\
\hline 19 & - & 180.4 & - & - & 182.2 & - \\
\hline 20 & $0.93, \mathrm{~s}$ & 17.6 & $1,5,9,10$ & $1.20, \mathrm{~s}$ & 27.7 & $1,5,9,10$ \\
\hline
\end{tabular}

${ }^{\text {a }}$ Recorded in $\mathrm{CDCl}_{3}$. The ${ }^{1} \mathrm{H}$ - and ${ }^{13} \mathrm{C}$ - spectra were recorded at $400 \mathrm{MHz}$ and the 2D-NMR at $600 \mathrm{MHz}$;

${ }^{\mathrm{b}}$ Recorded in $\mathrm{C}_{5} \mathrm{D}_{5} \mathrm{~N}$. The ${ }^{1} \mathrm{H}$ - and ${ }^{13} \mathrm{C}$ - spectra were recorded at $400 \mathrm{MHz}$ and the 2D-NMR at $600 \mathrm{MHz}$. 
Compound 2 was very similar to compound 1, but the epoxide ring of $\mathbf{1}$ was replaced by two hydroxyls and there was an additional double bond (Figure 1). The HMBC experiment (Figure 2 and Figure S10) showed that the olefinic proton at $\delta_{\mathrm{H}} 6.11$ (H-11) correlated with the carbons at $\delta_{\mathrm{C}} 168.0$ (C-9), $164.7(\mathrm{C}-12), 68.5(\mathrm{C}-8), 35.7(\mathrm{C}-10)$ and 27.7 (C-20); the proton of the oxygenated methine at $\delta_{\mathrm{H}}$ $5.40(\mathrm{H}-18)$ correlated with carbons at $\delta_{\mathrm{C}} 71.8(\mathrm{C}-7), 47.0(\mathrm{C}-5)$ and $35.7(\mathrm{C}-10)$; the protons at $\delta_{\mathrm{H}} 4.73$ (H-7) correlated with carbons at $\delta_{\mathrm{C}} 84.0$ (C-6) and 75.7 (C-17). These data, together with other correlations (Figure 2), established the planar structure. The NOESY experiment showed NOE interactions between

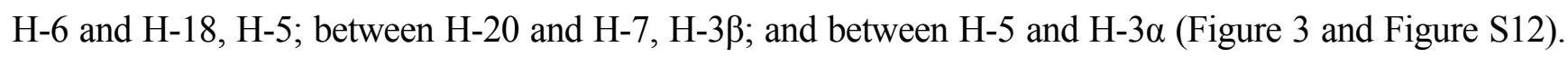
From comparison of the NMR data and the specific rotation data of compounds $\mathbf{1}$ and $\mathbf{2}$, together with a biogenetic perspective, the absolute configuration of $\mathbf{2}$ is proposed to be $4 S, 5 R, 6 S, 7 R, 8 R, 9 Z$, and 10S. Compound 2 was named as botryosphaerin $\mathrm{H}$.

\subsection{Biological Activities}

Compounds 1-9 were assayed for antifungal activity against Gaeumannomyces graminis, Fusarium moniliforme, Fusarium solani, Fusarium oxysporum and Pyricularia oryzae. Compounds 2 and $\mathbf{3}$ showed strong antifungal activity at $100 \mu \mathrm{g}$ /disk (Table 2). When assayed for nematicidal activity against Panagrellus redivivus and Caenorhabditis elegans, only botryosphaerin H (2) was active. Compound 2 killed $30 \%$ of $P$. redivivus and $28 \%$ of $C$. elegans at $400 \mathrm{mg} \cdot \mathrm{L}^{-1}$ at $24 \mathrm{~h}$, while the control ( $5 \%$ acetone) killed only $1.5 \%$ at $24 \mathrm{~h}$. As a positive control, avermectin was used and it killed $35 \%$ of $P$. redivivus and $92 \%$ of $C$. elegans at $400 \mathrm{mg} \cdot \mathrm{L}^{-1}$ at $24 \mathrm{~h}$.

Table 2. Antifungal activity of compounds 2 and $\mathbf{3}$ from Botryosphaeria sp. P483 at $100 \mu \mathrm{g} / \mathrm{disk}$.

\begin{tabular}{cccccc}
\hline \multirow{2}{*}{ Compounds } & \multicolumn{5}{c}{ Diameter of Fungus-Free Zone (mm) } \\
\cline { 2 - 6 } & G. graminis & F. solani & P. oryzae & F. moniliforme & F. oxysporum \\
\hline $\mathbf{2}$ & 9 & 7 & 7 & 8 & 8 \\
$\mathbf{3}$ & 12 & 10 & 10 & 11 & 13 \\
Carbendazim $(50 \mu \mathrm{g} / \mathrm{disk})$ & 14 & 18 & 15 & 17 & 15 \\
Control (methanol) & 0 & 0 & 0 & 0 & 0 \\
\hline
\end{tabular}

\section{Experimental Section}

\subsection{General}

The optical rotations were measured using a Jasco DIP-370 digital polarimeter (Tokyo, Japan). The UV spectra were recorded on a Shimadzu UV-2401PC spectrophotometer (Tokyo, Japan). The NMR spectra were obtained on Bruker AM-400 and Avance III 600 spectrometers (Karlsruhe, Germany). The ESI and HR-ESI-MS were recorded on Finnigan LCQ-Advantage (San Jose, CA, USA) and VG Auto-Spec-3000 mass spectrometers (Manchester, UK), and EI-MS was recorded on a Waters AutoSpec Premier P776 (Millford, MA, USA). Column chromatography was performed on silica gel G, silica gel 254, silica gel 200-300 mesh (Qingdao Marine Chemical Factory, Qingdao, China), silica gel H (Merck, Darmstadt, Germany) and Sephadex LH-20 (Amersham Pharmacia, Uppsala, Sweden). 


\subsection{Fungal Material}

The plant, Huperzia serrata (Thunb.) Trev., was collected in Xichou County, Yunnan Province, China, in July 2013. A voucher specimen (No. 20130710ZPJ) was deposited at the Herbarium of Kunming Institute of Botany (KUN), Chinese Academy of Sciences. The plant materials were washed under running tap water, sterilized successively with $75 \%$ ethanol for $1 \mathrm{~min}$ and $15 \%$ sodium hypochlorite for $15 \mathrm{~min}$, then rinsed in sterile water five times and cut into small pieces. These small pieces were incubated at $28^{\circ} \mathrm{C}$ on PDA media (potato $200 \mathrm{~g}$, dextrose $20 \mathrm{~g}$, agar $15 \mathrm{~g}$, distilled water $1 \mathrm{~L}$ ) and cultured until a colony or mycelium appeared around the segments. A strain, designated as F483, appeared after culturing for about two weeks and was isolated from the sterilized branch. The material was deposited in Kunming Institute of Botany, Chinese Academy of Sciences, Kunming, China.

\subsection{Fermentation, Extraction and Isolation}

Botryosphaeria sp. 483 was cultured on PDA at $28^{\circ} \mathrm{C}$ for 16 days. The solid culture $(30 \mathrm{~L}$, about 1000 Petri dishes) products were cut into small pieces and extracted three times with EtOAc/MeOH/AcOH $(80: 15: 5, v / v / v)$. The combined extracts were evaporated, then, the residue was suspended in water and extracted three times with EtOAc. The combined ethyl acetate extracts were evaporated and the residue $(27 \mathrm{~g})$ was subjected to column chromatography on silica gel G (200-300 mesh, $6.5 \times 45 \mathrm{~cm}$, $200 \mathrm{~g}$ ) eluted with a gradient of petroleum ether-EtOAc (from 10:1 to 6:4) followed by a gradient of $\mathrm{CHCl}_{3}-\mathrm{MeOH}$ (from 20:1, 10:1, 9:1, 8:2, 7:3, MeOH, each 1.5 L, $15 \mathrm{~mL} / \mathrm{min}$ ) from which 12 fractions were collected (Fr.1-Fr.12). Further chromatography of Fr.5 (705 mg) on Sephadex LH-20 (30 g, $2.5 \times 120 \mathrm{~cm}, 1 \mathrm{~mL} / \mathrm{min})$ eluted with $\mathrm{CHCl}_{3}-\mathrm{MeOH}(1: 1$, about $500 \mathrm{~mL})$ was conducted and four fractions were collected (Fr.5.1-Fr.5.4). Chromatography of Fr.5.4 (185 mg) on a column of silica gel $(\mathrm{GF} 254,3.5 \times 43 \mathrm{~cm}, 15 \mathrm{~g})$ eluted with petroleum ether-acetone (10:1) followed by purification on Sephadex LH-20 (30 g, $2.5 \times 120 \mathrm{~cm}, 1 \mathrm{~mL} / \mathrm{min}$ ) eluted with $\mathrm{MeOH}$ (about $500 \mathrm{~mL}$ ) gave compound 9 (3.1 mg).

Chromatography of Fr.6 (1.8 g) on Sephadex LH-20 (40 g, $2.5 \times 150 \mathrm{~cm}, 1 \mathrm{~mL} / \mathrm{min})$ eluted with $\mathrm{CHCl}_{3}-\mathrm{MeOH}(1: 1$, about $1000 \mathrm{~mL})$ was collected in four fractions (Fr.6.1-Fr.6.4). Purification of Fr.6.2 (480 mg) on a column of silica gel (GF254, $3.5 \times 43 \mathrm{~cm}, 20 \mathrm{~g})$ eluted with $\mathrm{CHCl}_{3}$-acetone (200:1, $800 \mathrm{~mL}$ ) gave compound 1 (13.4 mg). Chromatography of Fr.6.3 (600 mg) on silica gel (GF254, $3.5 \times 43 \mathrm{~cm}, 20 \mathrm{~g}$ ) eluted with a gradient of $\mathrm{CHCl}_{3}$-acetone (from 200:1, 100:2, 100:6, each $500 \mathrm{~mL}$, $1 \mathrm{~mL} / \mathrm{min})$ gave compound $6(6.4 \mathrm{mg})$.

Chromatography of Fr.7 (1.5 g) was subjected on Sephadex LH-20 (40 g, 2.5×150 cm, $1 \mathrm{~mL} / \mathrm{min})$ eluted with $\mathrm{CHCl}_{3}-\mathrm{MeOH}(1: 1$, about $800 \mathrm{~mL})$, and then separated on silica gel (GF254, $3.5 \times 60 \mathrm{~cm}$, $40 \mathrm{~g}$ ) eluted with petroleum ether-acetone (from 100:1, 50:1, 20:1, 10:1, each $200 \mathrm{~mL}$ ) to give, in three fractions, (Fr.7.1-Fr.7.3). Purification of Fr.7.2 (95 mg) on Sephadex LH-20 (30 g, 2.5×120 cm, $1 \mathrm{~mL} / \mathrm{min}$ ) eluted with $\mathrm{MeOH}$ (about $400 \mathrm{~mL}$ ) gave compound $7(11.5 \mathrm{mg}$ ).

Chromatography of Fr.8 (4.8 g) was conducted on Sephadex LH-20 (40 g, $2.5 \times 150 \mathrm{~cm}, 1 \mathrm{~mL} / \mathrm{min})$ eluted with $\mathrm{CHCl}_{3}-\mathrm{MeOH}(1: 1$, about $1000 \mathrm{~mL})$ and two fractions were collected (Fr.8.1, Fr.8.2). Purification of Fr.8.1 (1.2 g) on silica gel (GF254, $3.5 \times 60 \mathrm{~cm}, 40 \mathrm{~g})$ eluted with petroleum ether-acetone (4:1, $2000 \mathrm{~mL})$ gave compound $5(16.1 \mathrm{mg})$. Chromatography of Fr.8.2 (2.4 g) on silica gel (GF254, 
$3.5 \times 80 \mathrm{~cm}, 60 \mathrm{~g})$ eluted with a gradient of petroleum ether-acetone $(100: 7,9: 1,4: 1$, each $600 \mathrm{~mL})$ was followed by purification on silica gel (GF254, $3.5 \times 43 \mathrm{~cm}, 10 \mathrm{~g}$ ) eluted with $\mathrm{CHCl}_{3}-\mathrm{MeOH}$ (100:8, about $400 \mathrm{~mL}$ ) to give compound $\mathbf{8}(13.4 \mathrm{mg})$.

Further chromatography was conducted with Fr.9 (1.5 g) on silica gel (GF254, $3.5 \times 60 \mathrm{~cm}, 40 \mathrm{~g})$ eluted with a gradient of $\mathrm{CHCl}_{3}$-acetone $(100: 1,20: 1,10: 1,9: 1,4: 1$ each $300 \mathrm{~mL})$ and seven fractions were collected (Fr.9.1-Fr.9.7). Purification of Fr.9.3 (80 mg) on silica gel (GF254, $3.5 \times 43 \mathrm{~cm}, 10 \mathrm{~g}$ ) eluted with petroleum ether-acetone (8:1, about $400 \mathrm{~mL})$ gave compound 3 (30.4 mg). Purification of Fr.9.5 (600 mg) on silica gel (GF254, $3.5 \times 43 \mathrm{~cm}, 15 \mathrm{~g})$ eluted with $\mathrm{CHCl}_{3}$-acetone (50:1, about $600 \mathrm{~mL}$ ) gave compound 2 (4.3 mg) and chromatography of Fr.9.6 (213 mg) on Sephadex LH-20 (30 g, $2.5 \times 120 \mathrm{~cm}, 1 \mathrm{~mL} / \mathrm{min}$ ) eluted with $\mathrm{MeOH}$ (about $500 \mathrm{~mL}$ ) gave compound 4 (20.4 mg).

Botryosphaerin $G$ (1): $\mathrm{C}_{16} \mathrm{H}_{20} \mathrm{O}_{5}$, colorless needles; mp $225-226{ }^{\circ} \mathrm{C}[\alpha]_{D}^{21}=+63.0(c=0.16, \mathrm{MeOH})$; UV (MeOH) $\lambda_{\max }(\log \varepsilon): 200$ (2.73), 218 (2.70), 264 (1.96); ESI-MS: 293 [M + H] $]^{+}$; HR-ESI-MS $\left([\mathrm{M}+\mathrm{Na}]^{+} \mathrm{m} / z\right.$ 315.1203; calc. 315.1208$) .{ }^{1} \mathrm{H}-,{ }^{13} \mathrm{C}$ - and HMBC NMR see Table 1.

Crystal data: $\mathrm{C}_{16} \mathrm{H}_{20} \mathrm{O}_{5}, M_{\mathrm{r}}=292.32$, orthorhombic, $a=9.6701(3) \AA, b=9.8719(3) \AA$, $c=14.2941(4) \AA, \alpha=90.00^{\circ}, \beta=90.00^{\circ}, \gamma=90.00^{\circ}, V=1364.55(7) \AA^{3}, T=100(2) \mathrm{K}$, space group $P 2{ }_{1}{ }_{1}{ }_{1}, Z=4, \mu(\mathrm{CuK} \alpha)=0.871 \mathrm{~mm}^{-1}, 9249$ reflections measured, 2490 independent reflections $\left(R_{\text {int }}=0.0547\right)$. The final $R_{1}$ values were $0.0604(I>2 \sigma(I))$. The final $w R\left(F^{2}\right)$ values were 0.1513 $(I>2 \sigma(I))$. The final $R_{1}$ values were 0.0607 (all data). The final $w R\left(F^{2}\right)$ values were 0.1517 (all data). The goodness of fit on $F^{2}$ was 1.054. Flack parameter $=0.2(3)$. The Hooft parameter was 0.07(6) for 1024 Bijvoet pairs. Crystallographic data (excluding structure factors) have been deposited at the Cambridge Crystallographic Data Centre under the reference number CCDC 1411361. Copies of the data can be obtained free of charge on application to the CCDC, 12 Union Road, Cambridge CB2 IEZ, UK. Fax: +44-(0)1223-336033 or e-mail: deposit@ccdc.cam.ac.uk.

Botryosphaerin $H$ (2): $\mathrm{C}_{16} \mathrm{H}_{20} \mathrm{O}_{6}$, colorless amorphous solid; $[\alpha]_{D}^{21}=+38.0(c=0.17, \mathrm{MeOH})$; UV $(\mathrm{MeOH}) \lambda_{\max }(\log \varepsilon): 216$ (3.96); ESI-MS: $309[\mathrm{M}+\mathrm{H}]^{+}$; HR-ESI-MS $\left([\mathrm{M}+\mathrm{H}]^{+} \mathrm{m} / z\right.$ 309.1331; calc. 309.1338). ${ }^{1} \mathrm{H}-,{ }^{13} \mathrm{C}$ - and HMBC NMR see Table 1.

\subsection{Bioassays}

Antifungal activity was assayed against phytopathogenic fungi ( $G$. graminis, F. moniliforme, $F$. solani, F. oxysporum and P. oryzae) using the disk diffusion method [14], and carbendazim was as a positive control in antifungal activity. Determination of nematicidal activity against $P$. redivivus and C. elegans was based on the literature method [15]. Avermectin was as a positive control in nematicidal activity (Lynhi Fine Chemical Co. Ltd, Shijiazhuang, China).

\section{Conclusions}

A endophytic fungus, Botryosphaeria sp. P483, isolated from the Chinese Herbal Medicine Huperzia serrata, has been investigated. A systematic chemical study was performed and resulted in the isolation of new botryosphaerin $\mathrm{G}(\mathbf{1})$ and botryosphaerin $\mathrm{H}(\mathbf{2})$, along with seven known diterpenoids, 13,14,15,16-tetranorlabd-7-en-19,6ß:12,17-diolide (3), botryosphaerin A (4), 3a,10b-dimethyl-1,2,3,3a, 
5a,7,10b,10c-octahydro-5,8-dioxa-acephenanthrylene-4,9-dione (5), acrostalidic acid (6), botryosphaerin B, LL-Z1271 $\beta$ (8) and acrostalic acid (9). Compounds $\mathbf{2}$ and $\mathbf{3}$ showed antifungal activity and compound 2 showed weak nematicidal activity.

\section{Supplementary Materials}

Supplementary materials can be accessed at: http:/www.mdpi.com/1420-3049/20/09/16924/s1.

\section{Acknowledgments}

This work was supported by the National Basic Research Program of China (973 Program, 2013CB127505), the NSFC (31170061) and the Applied Basic Research Foundation of Yunnan Province (2013FA018). We acknowledge the Department of Instrumental Analysis of Kunming Institute of Botany for measuring the optical rotations, UV, NMR, X-ray and mass spectra.

\section{Author Contributions}

P.-J.Z. designed the research; Y.-M.C., Y.-H.Y., X.-N.L. and C.Z. performed the research and analyzed the data; P.-J.Z. wrote the paper. All authors read and approved the final manuscript.

\section{Conflicts of Interest}

The authors declare no conflict of interest.

\section{References}

1. Hyde, K.D.; Soytong, K. The fungal endophyte dilemma. Fungal Divers. 2008, 33, 163-173.

2. Tan, R.X.; Zou, W.X. Endophytes: A rich source of functional metabolites. Nat. Prod. Rep. 2001, $18,448-459$.

3. Gutierrez, R.M.; Gonzalez, A.M.; Ramirez, A.M. Compounds derived from endophytes: A review of phytochemistry and pharmacology. Curr. Med. Chem. 2012, 19, 2992-3030.

4. Kozikowski, A.P.; Tueckmantel, W. Chemistry, pharmacology, and clinical efficacy of the Chinese nootropic agent huperzine A. Acc. Chem. Res. 1999, 32, 641-650.

5. Zhao, P.J.; Fan, L.M.; Li, G.H.; Zhu, N.; Shen, Y.M. Antibacterial and antitumor macrolides from Streptomyces sp. Is9131. Arch. Pharm. Res. 2005, 28, 1228-1232.

6. Zhao, P.J.; Wang, H.X.; Li, G.H.; Li, H.D.; Liu, J.; Shen, Y.M. Secondary metabolites from endophytic Streptomyces sp. Lz531. Chem. Biodivers. 2007, 4, 899-904.

7. Yang, Y.H.; Fu, X.L.; Li, L.Q.; Zeng, Y.; Li, C.Y.; He, Y.N.; Zhao, P.J. Naphthomycins L-N, ansamycin antibiotics from Streptomyces sp. CS. J. Nat. Prod. 2012, 75, 1409-1413.

8. Barrero, A.F.; del Moral, J.F.Q.; Cuerva, J.M.; Cabrera, E.; Jimenez-Gonzalez, D. Preparation of bioactive podolactones via a new Pd-catalyzed bislactonisation reaction. Synthesis of oidiolactone C. Tetrahedron Lett. 2000, 41, 5203-5206.

9. Yuan, L.; Zhao, P. J.; Ma, J.; Lu, C.H.; Shen, Y.M. Labdane and tetranorlabdane diterpenoids from Botryosphaeria sp. MHF, an endophytic fungus of Maytenus hookeri. Helv. Chim. Acta 2009, 92, 1118-1124. 
10. Pettit, G.R.; Tan, R.; Herald, D.L.; Hamblin, J.; Pettit, R.K. Antineoplastic agents. 488. isolation and structure of Yukonin from a yukon territory fungus. J. Nat. Prod. 2003, 66, 276-278.

11. Hosoe, T.; Nozawa, K.; Lumley, T.C.; Currah, R.S.; Fukushima, K.; Takizawa, K.; Miyaji, M.; Kawai, K. Tetranorditerpene lactones, potent antifungal antibiotics for human pathogenic yeasts, from a unique species of Oidiodendron. Chem. Pharm. Bull. 1999, 47, 1591-1597.

12. Flack, H.D.; Bernardinelli, G. The use of X-ray crystallography to determine absolute configuration. Chirality 2008, 20, 681-690.

13. Hooft, R.W.; Straver, L.H.; Spek, A.L. Determination of absolute structure using Bayesian statistics on Bijvoet differences. J. Appl. Crystallogr. 2008, 41, 96-103.

14. Espinel-Ingroff, A.; White, T.; Pfaller, M.A. Antifungal agents and susceptibility tests. In Manual of Clinical Microbiology, 7th ed.; Murray, P.R., Ed.; American Society for Microbiology: Washington, DC, USA, 1999; pp. 1640-1652.

15. Li, G.H.; Duan, M.; Yu, Z.F.; Li, L.; Dong, J.Y.; Wang, X.B.; Guo, J.W.; Huang, R.; Wang, M.; Zhang, K.Q. Stereumin A-E, sesquiterpenoids from the fungus Stereum sp. CCTCC AF 207024. Phytochemistry 2008, 69, 1439-1445.

Sample Availability: Samples of the compounds 1-9 are available from the authors.

(C) 2015 by the authors; licensee MDPI, Basel, Switzerland. This article is an open access article distributed under the terms and conditions of the Creative Commons Attribution license (http://creativecommons.org/licenses/by/4.0/). 